\title{
Allergic Mastocytic Gastroenteritis and Colitis: An Unexplained Etiology in Chronic Abdominal Pain and Gastrointestinal Dysmotility
}

\author{
A. Akhavein M, ${ }^{1}$ N. R. Patel, ${ }^{2}$ P. K. Muniyappa, ${ }^{3,4}$ and S. C. Glover ${ }^{1,2}$ \\ ${ }^{1}$ Division of Gastroenterology, Hepatology, and Nutrition, University of Florida, 1600 SW Archer Road, HD512A, \\ P.O. Box 100214, Gainesville, FL 32610, USA \\ ${ }^{2}$ Section of Digestive Diseases and Nutrition, Department of Medicine, University of Illinois at Chicago, Chicago, IL 60612, USA \\ ${ }^{3}$ Department of Medicine, Mercy Medical Center, Chicago, IL 60616, USA \\ ${ }^{4}$ Department of Pediatrics, University of Illinois at Chicago, Chicago, IL 60612, USA
}

Correspondence should be addressed to S. C. Glover, sarah.glover@medicine.ufl.edu

Received 23 September 2011; Revised 17 November 2011; Accepted 18 November 2011

Academic Editor: Giovanni Barbara

Copyright () 2012 A. Akhavein M et al. This is an open access article distributed under the Creative Commons Attribution License, which permits unrestricted use, distribution, and reproduction in any medium, provided the original work is properly cited.

\begin{abstract}
Abdominal pain, bloating, early satiety, and changes in bowel habits are common presenting symptoms in individuals with functional GI disorders. Emerging data suggests that these symptoms may be associated with mast cell excess and/or mast cell instability in the GI tract. The aim of this retrospective study was to evaluate the contribution of mast cells to the aforementioned symptoms in individuals with a history of atopic disease. A retrospective chart review of individuals seen in a university GI practice was conducted and twenty-four subjects were identified. The majority had abdominal pain, early satiety, and nocturnal awakening. $66.7 \%$ and $37.5 \%$ had a history of environmental and/or food allergy. Solid gastric emptying was increased as were the mean number of mast cells reported on biopsies from the stomach, small bowel, and colon (>37/hpf) by CD117 staining. Mean whole blood histamine levels were uniformly elevated. This study suggests that in individuals with these characteristics, consideration should be given to staining their gastrointestinal biopsies for mast cells as this may provide them with relatively non-toxic but highly targeted treatment options. Allergic gastroenteritis and colitis may represent a third type of GI mast cell disorder along with mast cell activation syndrome and mastocytic enterocolitis.
\end{abstract}

\section{Introduction}

Chronic abdominal pain together with symptoms of altered gastrointestinal motility defines a rather common presenting tableau in the gastroenterology practice, shared by idiopathic gastroparesis (IGP) and functional GI disorders such as irritable bowel syndrome (IBS) and functional dyspepsia (FD), among others.

IBS is defined as a chronic continuous or remittent gastrointestinal illness characterized by frequent unexplained symptoms that include abdominal pain, bloating, and bowel disturbance, which may be either diarrhea or constipation or an erratic bowel habit that has features of both. IBS is a common illness with an overall prevalence of about 10 $15 \%$ within the general population [1-3]. Similar to FD and IGP, IBS also presents with chronic abdominal pain and symptoms of GI dysmotility (GID). Dysmotility is one of the proposed mechanisms in the pathophysiology of IBS $[4,5]$.

On the other hand, one of the most studied immune cells associated with IBS is the mast cell. Increased numbers of GI mast cells have been documented in a subset of IBS patients throughout the small and large intestine [6]: in the duodenum [7], jejunum [8], ileum $[9,10]$, cecum $[11,12]$, ascending and descending colon, and rectum [10]. Mast cells and their mediators play a potential role in the pathophysiology of IBS by causing sensorimotor dysfunction of the gut through interactions with the enteric nervous system [13-15]. Moreover, IBS has been increasingly linked to food allergy [16-19] in which mast cells play a critical role [20].

Another functional GI disorder with chronic abdominal pain and GID symptoms is functional dyspepsia (FD), 
characterized by abdominal pain and symptoms of GID, such as early satiety and postprandial fullness, without any evidence of structural diseases.

The goal of this retrospective caseseries was to describe a subgroup of patients whose main symptomatology consisted of chronic abdominal pain and symptoms suggestive of GID, who had associated increased numbers of GI mast cells, history of food/environmental allergy, nocturnal awakening, and/or mast cell instability. Gastrointestinal mast cells excess is defined as the presence of greater than 20 mast cells per high-power field of microscopy in the GI tract mucosa. Mast cell instability is marked by an increase in mast cells mediators' release, for example, increased circulating histamine levels.

\section{Methods}

A retrospective chart review of the patients seen at the University of Illinois GI clinics between years 2006 and 2009 was performed. Inclusion criteria were defined as follows:

(1) patients with GID symptoms or symptoms of functional disorders such as IBS or FD,

(2) patients with available GI tract mucosal biopsies and CD117 staining of the specimens for mast cell evaluation.

The data extracted from the patients' charts included the following:

(i) demographic data including age, sex, and race,

(ii) history and physical examination with emphasis on GI symptoms: abdominal pain, early satiety, diarrhea, constipation, abdominal bloating, nocturnal awakening, history of food/environmental allergy, history of immunotherapy, and presence of succussion splash,

(iii) laboratory data including CBC, ESR, CRP, serum IgE, whole-blood histamine, and stool studies,

(iv) history of medications, including improvement in GI complaints after being put on medication,

(v) pathology reports and histological slides,

(vi) radiology reports including nuclear medicine studies and CT scans,

(vii) results of food allergy testing by RAST (radioallergosorbent test) or SPT (skin prick testing),

(viii) CD-25 marker assessment and serum tryptase levels measurement were not recorded since these had already been studied in previous papers.

Staining options available for mast cells include toluidine blue staining, tryptase staining, the Giemsa staining, and CD117 marker detection [21]. Unlike CD25 which is expressed on neoplastic mast cells [22], the CD117 marker (The $c$-Kit antigen) is detectable both in normal and neoplastic mast cells either by flow cytometry or by immunohistochemistry. The stem cell factor (SCF) receptor Kit (CD117) antigen is expressed on all types of mast cells
TABLE 1: Summary of signs and symptoms of the subjects $(n=24)$.

\begin{tabular}{lccc}
\hline Sign or Symptom & Present & Not Present & Not Available \\
\hline Abdominal pain & $24(100 \%)$ & $0(0 \%)$ & $0(0 \%)$ \\
Early satiety/bloating & $23(95.8 \%)$ & $1(4.2 \%)$ & $0(0 \%)$ \\
Constipation & $9(37.5 \%)$ & $15(62.5 \%)$ & $0(0 \%)$ \\
Diarrhea & $11(45.8 \%)$ & $13(54.2 \%)$ & $0(0 \%)$ \\
Succussion splash & $13(54.2 \%)$ & $5(20.8 \%)$ & $6(25 \%)$ \\
Nocturnal awakening & $19(79.2 \%)$ & $0(0 \%)$ & $5(20.8 \%)$ \\
\hline
\end{tabular}

TABLE 2: Summary of the allergic history of the subjects $(n=24)$.

\begin{tabular}{lccc}
\hline History & Positive & Negative & Not available \\
\hline Immunotherapy & $8(33.3 \%)$ & $16(66.7 \%)$ & $0(0 \%)$ \\
Food allergy & $9(37.5 \%)$ & $11(45.8 \%)$ & $4(16.7 \%)$ \\
Environmental allergy & $16(66.7 \%)$ & $2(8.3 \%)$ & $6(25 \%)$ \\
\hline
\end{tabular}

independent of maturation and activation status. Therefore, CD117/Kit was used in these patients as a robust mast cell marker antigen (Figure 1) [23]. The biopsies taken were mucosal, so the CD117 (+) cells detected were mucosal mast cells and not interstitial cells of Cajal or submucosal mast cells. CD-25 marker assessment and serum tryptase levels measurement were not done since these had already been studied in previous papers $[20,24]$.

Delayed gastric emptying was defined as emptying time greater than 200 minutes on solid-phase gastric emptying scan.

The cutoff point for increased number of GI mucosalmast cells was defined as more than 20 mast cells per high power field (hpf) on microscopy using immunostaining for CD117. Other inflammatory and allergy parameters collected included serum IgE and whole-blood histamine levels. Normal whole-blood histamine level range was defined by our lab as less that $300 \mathrm{nmol} / \mathrm{L}$, which is in concordance with the ranges proposed in the literature [25]. Normal serum IgE level range was defined by our lab as 10-179 IU/mL.

The collected data was analyzed using descriptive statistical methods, with means, standard deviations, and standard errors being reported.

\section{Results}

This population consisted of 21 females and 3 males, with an age range of 16 to 64 and a mean age of 34.5. All the patients had a history of abdominal pain, with $45.8 \%$ of them having diarrhea and $37.5 \%$ having constipation (Table 1). Of subjects with available data, 5.5\% had a history of food allergy only, $50 \%$ had a history of environmental allergies only, and $43.7 \%$ had both. Specific details of patients' histories and symptoms are summarized in Tables 1 and 2.

For the 14 out of 24 patients who had a gastric emptying scintigraphy done to explain their upper GI symptoms, the mean emptying time was 204 minutes on the solidphase gastric emptying scan (Figure 2 and Table 3 ). The scintiscanning was performed over 90 minutes using the 


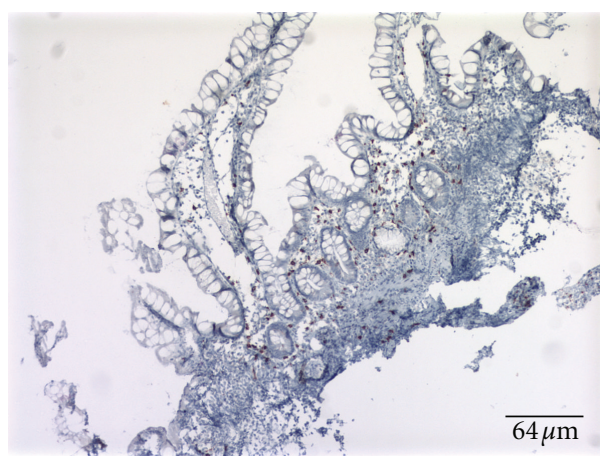

(a)

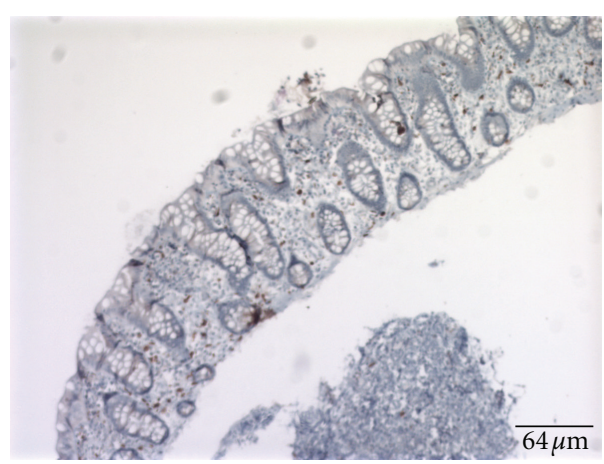

(b)

Figure 1: Anti-CD117 staining was used to identify the mast cells. Images of positive CD117 in the small bowel (a) and the colon (b). Positive cells are brown. Abnormal CD117 is considered to be more than 20 cells per high-power field (hpf). Bar length is equal to $64 \mu \mathrm{m}$.

TABLE 3: Summary of solid-phase gastric emptying time (minutes).

\begin{tabular}{ll}
\hline & $\begin{array}{l}\text { Solid-phase gastric } \\
\text { emptying time (min) }\end{array}$ \\
\hline $\begin{array}{l}\text { Total number of values } \\
\text { available }\end{array}$ & 14 \\
Minimum & 10.0 \\
25\% percentile & 86.5 \\
Median & 132.0 \\
$75 \%$ percentile & 338.75 \\
Maximum & 500.0 \\
Mean & 204.357 \\
Std. deviation & 162.67 \\
Std. error & 43.4753 \\
Lower 95\% CI* of mean & 110.434 \\
Upper 95\% CI* of mean & 298.28 \\
\hline
\end{tabular}

${ }^{*}$ CI: confidence interval.

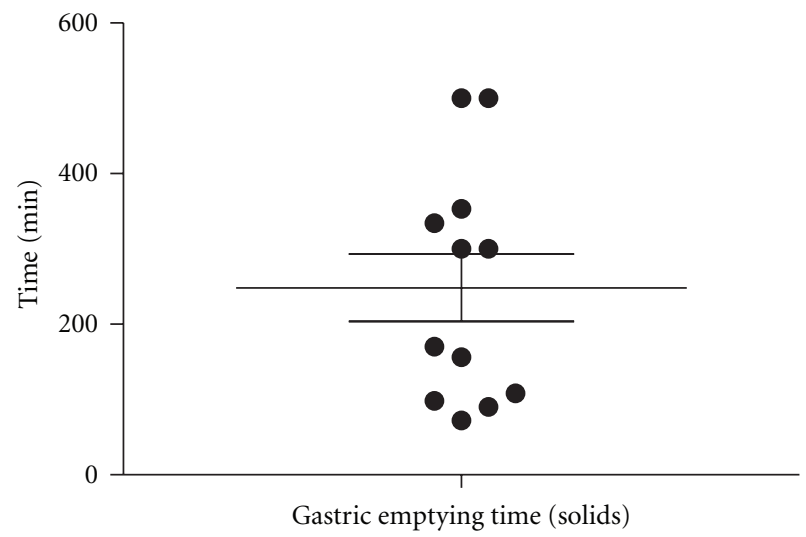

FIGURE 2: Frequency distribution of solid-phase gastric emptying times. Scan was performed over 90 minutes. Data was available for 14 of 24 patients. Mean emptying time was 204 minutes. Emptying times greater than 200 minutes are suggestive of gastroparesis.

standard protocol at the University of Illinois Nuclear Medicine Division at that time (Figure 2 and Table 3 ).

The mean number of the mast cells in the stomach was 39 cells per high-power field (hpf), in the small bowel was 57

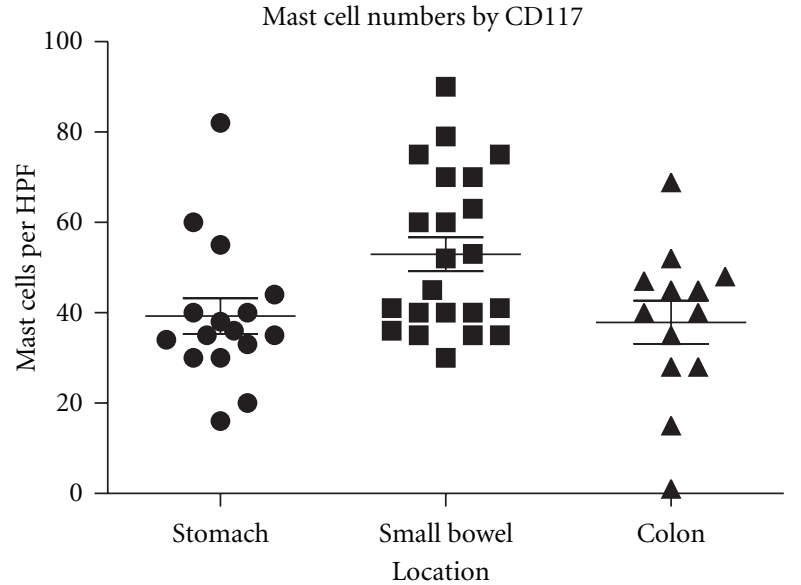

FIGURE 3: The distribution of mast cells based on the location in the GI tract. Mean number in the stomach was 39 cells per high-power field (hpf). Mean number in the small bowel was 57 cells per hpf. Mean number in the colon was 37 cells per hpf.

cells per hpf, and in the colon was 37 cells per hpf (Figure 3 and Table 4). Unlike dense aggregates of mast cells seen in systemic mastocytosis biopsies [26], our specimens showed diffused mast cell infiltration of the mucosa (Figure 1).

The inflammatory and allergy markers studied included serum IgE level and whole-blood histamine levels. The mean serum IgE level was $213 \mathrm{IU} / \mathrm{mL}$, and the median was $37 \mathrm{IU} / \mathrm{mL}$. The mean whole-blood histamine level was $798 \mathrm{nmol} / \mathrm{L}$ (Figure 4 and Table 5). Elevated serum IgE levels were seen in $13.6 \%$ of patients with available data, and $95 \%$ of patients with available data had an elevated whole-blood histamine level. Serum IgE levels data was available for 22 patients, and whole-blood histamine levels data was available for 20 patients. Summary of collected values is shown in Tables 3, 4, and 5 and Figures 2, 3, and 4.

\section{Limitations}

The study's retrospective design imposed limitations inherent in the nature of such studies. Therefore, the date 
TABLE 4: Summary of the GI tract biopsy/CD117 staining results: number of mast cells per high power field (hpf).

\begin{tabular}{lccc}
\hline \# Mast cells/hpf & Stomach & Small Bowel & Colon \\
\hline Total number of values available & 16 & 22 & 13 \\
Minimum & 16.0 & 30.0 & 3.0 \\
25\% percentile & 30.75 & 39.0 & 28.0 \\
Median & 35.5 & 48.5 & 40.0 \\
$75 \%$ percentile & 43.0 & 70.0 & 47.5 \\
Maximum & 82.0 & 52.9545 & 68.8333 \\
Mean & 39.25 & 17.5105 & 37.9103 \\
Std. deviation & 15.7628 & 3.73325 & 17.177 \\
Std. error & 3.94071 & 45.1908 & 4.76404 \\
Lower 95\% CI* of mean & 30.8506 & 60.7183 & 27.5304 \\
Upper 95\% CI* of mean & 47.6494 & 48.2902 \\
\hline
\end{tabular}

${ }^{*}$ CI: confidence interval.

TABLE 5: Summary of serum IgE levels and whole blood histamine levels.

\begin{tabular}{lll}
\hline & $\begin{array}{l}\text { Total IgE } \\
\mathrm{IU} / \mathrm{mL}\end{array}$ & $\begin{array}{l}\text { Histamine } \\
\mathrm{nmol} / \mathrm{L}\end{array}$ \\
\hline $\begin{array}{l}\text { Total number of values } \\
\text { available }\end{array}$ & 22 & 20 \\
Minimum & 3.0 & $<300$ \\
25\% percentile & 14.75 & 547.75 \\
Median & 37.0 & 776.0 \\
75\% percentile & 90.0 & 1025.75 \\
Maximum & 1556.0 & 1597.0 \\
Mean & 213.409 & 798.1 \\
Std. deviation & 465.573 & 319.255 \\
Std. error & 99.2605 & 71.3876 \\
Lower 95\% CI* of mean & 6.98497 & 648.682 \\
Upper 95\% CI* of mean & 419.833 & 947.518 \\
\hline * confidence interval. & &
\end{tabular}

presented herein is of a descriptive nature. In spite of this, this current study serves as a basis for future cohort studies and clinical trials that evaluate the role of mast cells in GI disease.

This study uses data from a 90-minute gastric emptying scintigraphy scans. At the time these individuals were seen, the 90-minute gastric emptying study was standard protocol in the University of Illinois Nuclear Medicine division. The authors acknowledge that the 4-hour gastric emptying scan is the new standard of care [27-29].

\section{Discussion}

This paper describes a distinct group of GI patients with chronic abdominal pain and symptoms of GI dysmotility, features that mimic the features of entities such as IBS, FD, or IGP, but who actually suffer from gastrointestinal mast cell excess and/or instability. These patients frequently exhibit features of mast cell excess, including positive history of food and/or environmental allergies, signs and symptoms such as flushing, pruritus, tachycardia, asthma, headache, or dermatographism, and suggestive lab data such as elevated

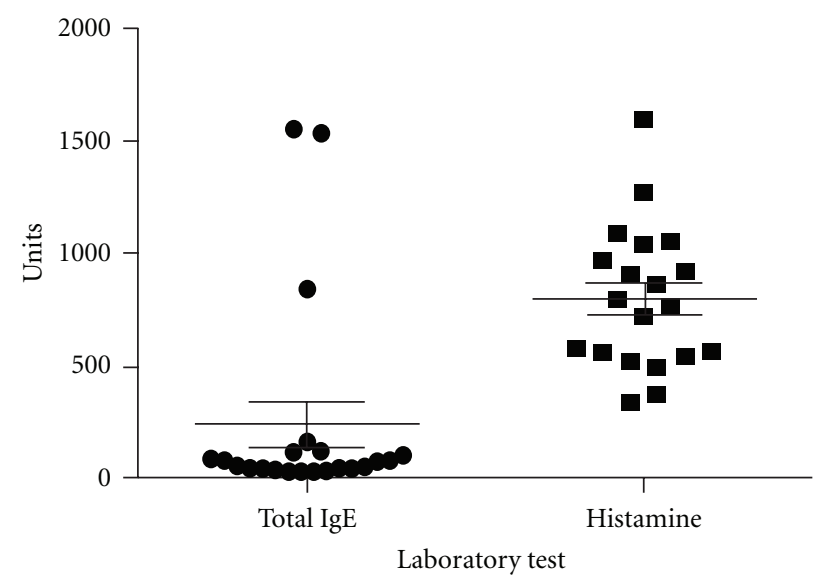

FIGURE 4: Frequency distribution of serum IgE level and whole blood Histamine levels in the group. Mean IgE level was $213 \mathrm{IU} / \mathrm{mL}$ and and Median was $37 \mathrm{IU} / \mathrm{mL}$. Mean Histamine level was $798 \mathrm{nmol} / \mathrm{L}$. Data was available for 22 and 20 patients, respectively.

serum IgE levels or whole-blood histamine levels greater than $300 \mathrm{nmol} / \mathrm{L}[24,25,30]$. The corresponding plasma histamine level would be $3 \mathrm{nmol} / \mathrm{L}$ [25].

In the current literature, there are two loosely defined entities associated with increased numbers on mast cells on gastrointestinal biopsies. The first of these is mastocytic enterocolitis. Mastocytic enterocolitis is defined as more than 20 mast cells per high-power field by tryptase stain in individuals with chronic diarrhea of unknown etiology [20]. Mast cell activation syndrome occurs in individuals who have symptoms associated with mast cell instability including dermatographism, flushing, mental fog, or poor concentration, abdominal pain, diarrhea, anaphylaxis, and asthma who have a dramatic improvement in their symptoms in response to antihistamines and $\mathrm{H} 2$ blockers. Intriguingly, in this group, the numbers of mast cells on gastrointestinal biopsies by CD117 or tryptase were between 17 and 23 cells per highpower field [24]. These distinguishing features between our cohort and the two other published GI mast cell disorders are summarized in Table 6. 
TABle 6: Comparison between different GI mast cell diseases [20, 24].

\begin{tabular}{llll}
\hline & Cardinal symptoms & Number of mast cells/HPF & Serum markers \\
\hline $\begin{array}{l}\text { Mastocytic } \\
\text { enterocolitis }\end{array}$ & Abdominal pain, diarrhea & $>20$ & N/A \\
$\begin{array}{l}\text { Mast cell Activation } \\
\text { syndrome }\end{array}$ & $\begin{array}{l}\text { Abdominal pain, dermatographism, } \\
\text { flushing }\end{array}$ & $17-23$ & Serum tryptase \\
$\begin{array}{l}\text { Allergic mastocytic } \\
\begin{array}{l}\text { Gastroenteritis and } \\
\text { colitis }\end{array}\end{array}$ & $\begin{array}{l}\text { Abdominal pain, dysmotility } \\
\text { symptoms (e.g., early satiety, } \\
\text { bloating), nocturnal awakening }\end{array}$ & $>40$ & Histamine, IgE \\
\hline
\end{tabular}

As mentioned in the introduction to this paper, IBS has been associated with elevated mast cell numbers [6$9,11,12]$ and food allergy [16-19]. The cohort we describe herein has several features that distinguish it from mastocytic enterocolitis and mast cell activation syndrome. They are (1) documented GI dysmotility, (2) nocturnal awakening, (3) elevated histamine levels, (4) history of food or environmental allergy, (5) significantly higher numbers of mast cells per high-power field, that is, approximately 40 per high-power field on average. As such, we propose that our cohort of patients represents a possible third entity wherein elevated numbers of mast cells are noted on gastrointestinal biopsies in patients who have previously been classified as having IBS, functional dyspepsia, or idiopathic gastroparesis. We suggest that this disorder could potentially be referred to as allergic mastocytic gastroenteritis and colitis as these patients have documented allergies, elevated histamine levels, and nocturnal awakening. Nocturnal awakening has been associated with uncontrolled asthma [31] and in our cohort differentiates our patients from those with true IBS as defined by ROME III criteria. We believe that as in asthma, nocturnal awakening in our cohort was due to a spike in leukotrienes.

As other authors have suggested, treatment of gastrointestinal mast cell disease should be focused on blockade of $\mathrm{H} 1$ and $\mathrm{H} 2$ and mast cell stabilization. These therapeutic approaches include $\mathrm{H} 1$ receptor antagonists such as diphenhydramine (Benadryl), cetirizine (Zyrtec), loratadine (Claritin) [13], H2 receptor antagonists such as ranitidine (Zantac) and famotidine (Pepcid), and mast cell membrane stabilizers such as oral cromolyn sodium (Gastrocrom) [32-36]. Because of the nocturnal awakening observed in our patients, we would also suggest adding an antileukotriene such as montelukast (Singulair) or a 5liopoxygenase inhibitor such as zileuton extended-release tablets (Zyflo CR). In patients with more severe symptoms that significantly disrupt their activities of daily living and/or sleep, we suggest the addition of budesonide (Entocort) or a short course of prednisone.

In conclusion, herein we report a cohort of patients with gastrointestinal mast cell disease separate and distinct from systemic mastocytosis and the aforementioned GI mast cell disorders. Further characterization of this possible disorder is needed in order to clearly distinguish these patients from those with IBS or systemic mastocytosis.

\section{Conflict of Interests}

The authors declare that they have no conflict of interests.

\section{References}

[1] A. P. Hungin, L. Chang, G. R. Locke, E. H. Dennis, and V. Barghout, "Irritable bowel syndrome in the United States: prevalence, symptom patterns and impact," Alimentary Pharmacology and Therapeutics, vol. 21, no. 11, pp. 1365-1375, 2005.

[2] N. J. Talley, A. R. Zinsmeister, C. Van Dyke, and L. J. Melton, "Epidemiology of colonic symptoms and the irritable bowel syndrome," Gastroenterology, vol. 101, no. 4, pp. 927-934, 1991.

[3] D. A. Drossman, Z. Li, E. Andruzzi et al., "U.S. Householder survey of functional gastrointestinal disorders. Prevalence, sociodemography, and health impact," Digestive Diseases and Sciences, vol. 38, no. 9, pp. 1569-1580, 1993.

[4] M. Kanazawa, M. Hongo, and S. Fukudo, "Visceral hypersensitivity in irritable bowel syndrome," Journal of Gastroenterology and Hepatology, vol. 26, supplement 3, pp. 119-121, 2011.

[5] L. Dobrek and P. J. Thor, "Pathophysiological concepts of functional dyspepsia and irritable bowel syndrome future pharmacotherapy," Acta Poloniae Pharmaceutica, vol. 66, no. 5, pp. 447-460, 2009.

[6] M. M. Walker, A. Warwick, C. Ung, and N. J. Talley, "The role of eosinophils and mast cells in intestinal functional disease," Current Gastroenterology Reports, vol. 13, no. 4, pp. 323-330, 2011.

[7] M. M. Walker, N. J. Talley, M. Prabhakar et al., "Duodenal mastocytosis, eosinophilia and intraepithelial lymphocytosis as possible disease markers in the irritable bowel syndrome and functional dyspepsia," Alimentary Pharmacology and Therapeutics, vol. 29, no. 7, pp. 765-773, 2009.

[8] M. Guilarte, J. Santos, I. de Torres et al., "Diarrhoeapredominant IBS patients show mast cell activation and hyperplasia in the jejunum," Gut, vol. 56, no. 2, pp. 203-209, 2007.

[9] A. P. Weston, W. L. Biddle, P. S. Bhatia, and P. B. Miner Jr., "Terminal ileal mucosal mast cells in irritable bowel syndrome," Digestive Diseases and Sciences, vol. 38, no. 9, pp. 1590-1595, 1993.

[10] J. H. Park, P. L. Rhee, H. S. Kim et al., "Mucosal mast cell counts correlate with visceral hypersensitivity in patients with diarrhea predominant irritable bowel syndrome," Journal of Gastroenterology and Hepatology, vol. 21, no. 1, pp. 71-78, 2006.

[11] M. O'Sullivan, N. Clayton, N. P. Breslin et al., "Increased mast cells in the irritable bowel syndrome," Neurogastroenterology and Motility, vol. 12, no. 5, pp. 449-457, 2000.

[12] T. Piche, M. C. Saint-Paul, R. Dainese et al., "Mast cells and cellularity of the colonic mucosa correlated with fatigue and depression in irritable bowel syndrome," Gut, vol. 57, no. 4, pp. $468-473,2008$. 
[13] D. B. Ramsay, S. Stephen, M. Borum, L. Voltaggio, and D. B. Doman, "Mast cells in gastrointestinal disease," Gastroenterology and Hepatology, vol. 6, no. 12, pp. 772-777, 2010.

[14] G. Barbara, V. Stanghellini, R. De Giorgio, and R. Corinaldesi, "Functional gastrointestinal disorders and mast cells: implications for therapy," Neurogastroenterology and Motility, vol. 18, no. 1, pp. 6-17, 2006.

[15] G. Barbara, V. Stanghellini, R. De Giorgio et al., "Activated mast cells in proximity to colonic nerves correlate with abdominal pain in irritable bowel syndrome," Gastroenterology, vol. 126, no. 3, pp. 693-702, 2004.

[16] M. Park and M. Camilleri, "Is there a role of food allergy in irritable bowel syndrome and functional dyspepsia? A systematic review," Neurogastroenterology and Motility, vol. 18, no. 8, pp. 595-607, 2006.

[17] A. Shiotani, "Role of allergy in irritable bowel syndrome," Nippon Rinsho, vol. 64, no. 8, pp. 1532-1535, 2006.

[18] S. Zar, D. Kumar, and D. Kumar, "Role of food hypersensitivity in irritable bowel syndrome," Minerva Medica, vol. 93, no. 5, pp. 403-412, 2002.

[19] A. Morcos, T. Dinan, and E. M. Quigley, "Irritable bowel syndrome: role of food in pathogenesis and management," Journal of Digestive Diseases, vol. 10, no. 4, pp. 237-246, 2009.

[20] S. Jakate, M. Demeo, R. John, M. Tobin, and A. Keshavarzian, "Mastocytic enterocolitis: increased mucosal mast cells in chronic intractable diarrhea," Archives of Pathology and Laboratory Medicine, vol. 130, no. 3, pp. 362-367, 2006.

[21] J. Khoo, C. K. Rayner, K. L. Jones, and M. Horowitz, "Pathophysiology and management of gastroparesis," Expert Review of Gastroenterology and Hepatology, vol. 3, no. 2, pp. 167-181, 2009.

[22] H. P. Hahn and J. L. Hornick, "Immunoreactivity for CD25 in gastrointestinal mucosal mast cells is specific for systemic mastocytosis," American Journal of Surgical Pathology, vol. 31, no. 11, pp. 1669-1676, 2007.

[23] P. Valent, S. Cerny-Reiterer, H. Herrmann et al., "Phenotypic heterogeneity, novel diagnostic markers, and target expression profiles in normal and neoplastic human mast cells," Best Practice and Research, vol. 23, no. 3, pp. 369-378, 2010.

[24] M. J. Hamilton, J. L. Hornick, C. Akin, M. C. Castells, and N. J. Greenberger, "Mast cell activation syndrome: a newly recognized disorder with systemic clinical manifestations," Journal of Allergy and Clinical Immunology, vol. 128, no. 1, pp. 147-152, 2011.

[25] A. D. Hogan and L. B. Schwartz, "Markers of mast cell degranulation," Methods, vol. 13, no. 1, pp. 43-52, 1997.

[26] P. Valent, C. Akin, W. R. Sperr et al., "Diagnosis and treatment of systemic mastocytosis: state of the art," British Journal of Haematology, vol. 122, no. 5, pp. 695-717, 2003.

[27] T. L. Abell, M. Camilleri, K. Donohoe et al., "Consensus recommendations for gastric emptying scintigraphy: a joint report of the American neurogastroenterology and motility society and the society of nuclear medicine," American Journal of Gastroenterology, vol. 103, no. 3, pp. 753-763, 2008.

[28] G. Tougas, E. Y. Eaker, T. L. Abell et al., "Assessment of gastric emptying using a low fat meal: establishment of international control values," American Journal of Gastroenterology, vol. 95, no. 6, pp. 1456-1462, 2000.

[29] Q. Hou, Z. Lin, R. Dusing, B. J. Gajewski, R. W. McCallum, and M. S. Mayo, "Optimizing the diagnostic power with gastric emptying scintigraphy at multiple time points," BMC Medical Research Methodology, vol. 11, p. 84, 2011.
[30] M. Feldman, L. S. Friedman, and M. H. Sleisenger, Sleisenger \& Fordtran's Gastrointestinal and Liver Disease: Pathophysiology, Diagnosis, Management, Saunders, Philadelphia, pa, USA, 7th edition, 2002.

[31] E. R. Sutherland, "Nocturnal asthma: underlying mechanisms and treatment," Current Allergy and Asthma Reports, vol. 5, no. 2, pp. 161-167, 2005.

[32] F. K. Friedenberg and H. P. Parkman, "Delayed gastric emptying: whom to test, how to test, and what to do," Current Treatment Options in Gastroenterology, vol. 9, no. 4, pp. 295304, 2006.

[33] G. F. Stefanini, E. Prati, M. C. Albini et al., "Oral disodium cromoglycate treatment on irritable bowel syndrome: an open study on 101 subjects with diarrheic type," American Journal of Gastroenterology, vol. 87, no. 1, pp. 55-57, 1992.

[34] H. Zachariae, T. Herlin, and P. O. Larsen, "Oral disodium cromoglycate in mastocytosis," Acta Dermato-Venereologica, vol. 61 , no. 3, pp. 272-273, 1981.

[35] O. Leri, S. Tubili, F. G. De Rosa et al., "Management of diarrhoeic type of irritable bowel syndrome with exclusion diet and disodium cromoglycate," Inflammopharmacology, vol. 5, no. 2, pp. 153-158, 1997.

[36] H. Sokol, S. Georgin-Lavialle, C. Grandpeix-Guyodo et al., "Gastrointestinal involvement and manifestations in systemic mastocytosis," Inflammatory Bowel Diseases, vol. 16, no. 7, pp. 1247-1253, 2010. 


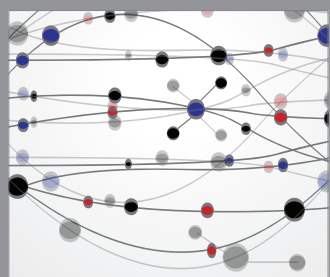

The Scientific World Journal
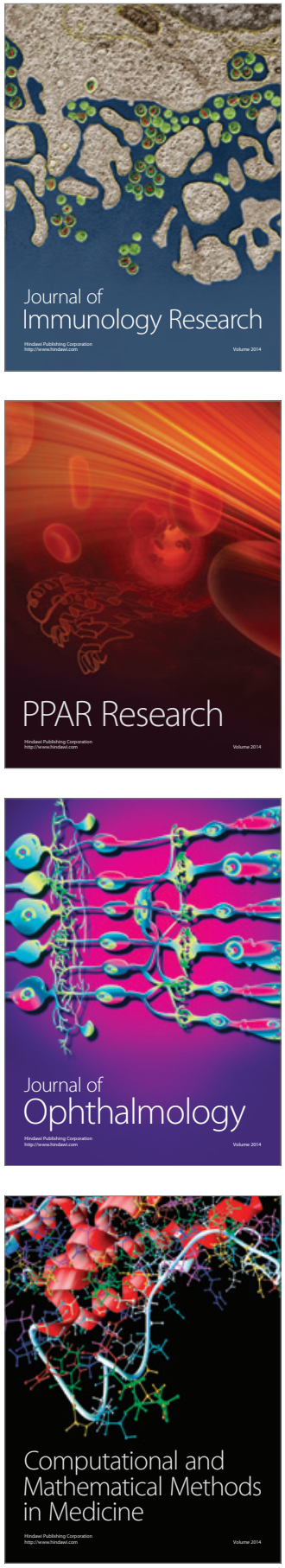

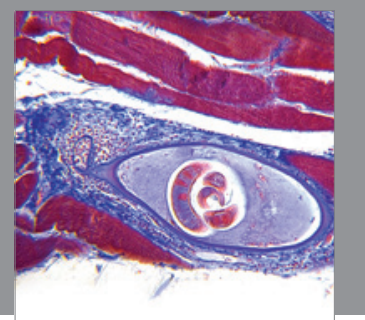

Gastroenterology

Research and Practice
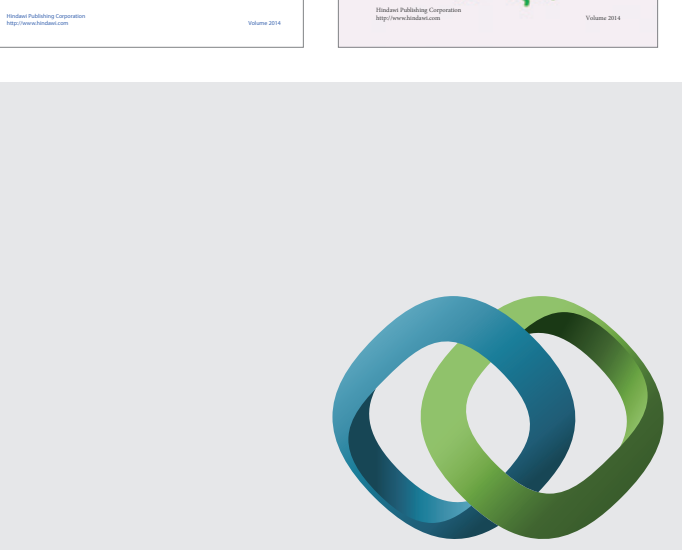

\section{Hindawi}

Submit your manuscripts at

http://www.hindawi.com
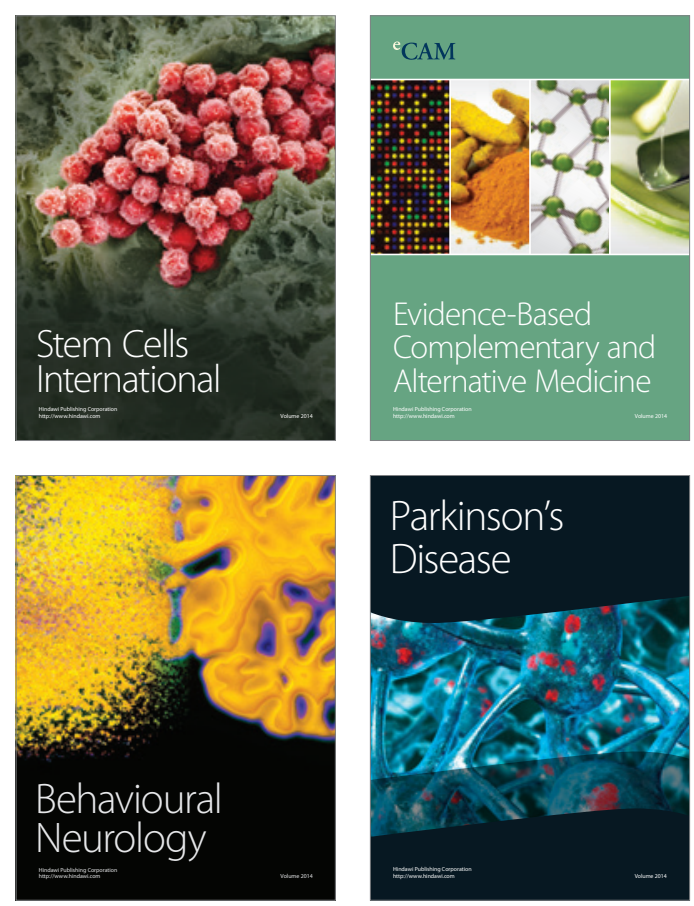

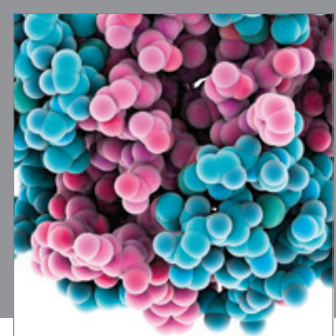

Journal of
Diabetes Research

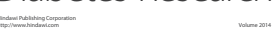

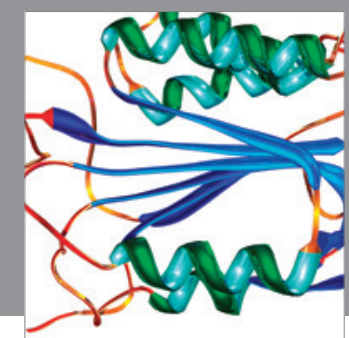

Disease Markers
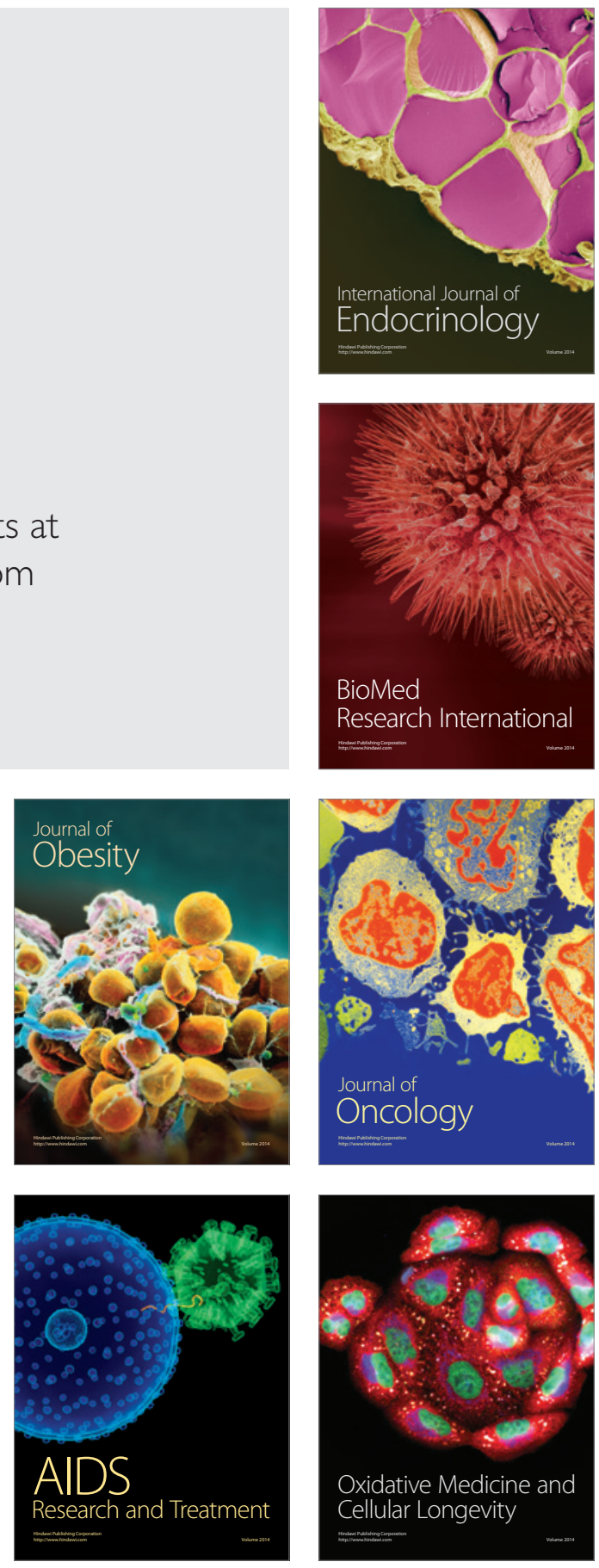